\title{
Metal Biosorption Equilibria in a Ternary System
}

\author{
K. H. Chong and B. Volesky* \\ Department of Chemical Engineering, McGill University, 3480 University \\ Street, Montreal, Quebec, H3A 2 A7 Canada
}

Received June 7, 1995/Accepted October 4, 1995

Equilibrium metal uptake performance of a biosorbent prepared from Ascophyllum nodosum seaweed biomass was studied using aqueous solutions containing copper, cadmium, and zinc ions in binary and ternary mixtures. Triangular equilibrium diagrams can graphically represent all the ternary equilibrium sorption data. Application of the multicomponent Langmuir model to describe the three-metal system revealed its nonideal characteristics, whereby the value of apparent dissociation constants for the respective metals differed for each system. This restricted the prediction of the ternary equilibria from the binary systems. However, some predictions of the ternary system behavior from the model were consistent with experimental data and with conclusions postulated from the three possible binary subsystems. (c) 1996 John Wiley \& Sons, Inc.

Key words: Biosorption - Ascophyllum nodosum - cadmium $\cdot$ copper $\cdot$ zinc $\cdot$ three-metal system

\section{INTRODUCTION}

Biosorption, the metabolism-independent binding of heavy metals to nonliving biomass, has been explored for its potential in removing toxic heavy metals from aqueous solutions. For economic reasons, of particular interest is biomass of certain ubiquitous seaweeds capable of sequestering high quantities of metals. Lead and cadmium, for instance, have been effectively removed from very dilute solutions by dried biomass of common brown marine algae such as Ascophyllum and Sargas. sum which accumulate more than $30 \%$ of biomass dry weight in the metal. ${ }^{25}$

A major consideration preceding the implementation of any sorption operation is the equilibrium distribution of ionic components between the solid and liquid phases for a particular sorption system. Aspects of sorption equilibria using algal biosorbent have been examined mainly experimentally. However, the majority of published work on biosorption is concerned with one-metal sorption system. ${ }^{7-9}$ Very little information is available for two metal biosorption systems. ${ }^{13,14,23}$ Because biosorption is foreseen to be implemented in the fields of water treatment and hydrometallurgy, where complex multicomponent metal systems are common, more work is required. Reliable knowledge, correlation, and analysis of multicomponent equilibrium data are essential for

\footnotetext{
*To whom all correspondence should be addressed.
}

the proper understanding of biosorption column dynamics and for further development of biosorption separation processes representing a whole new area in environmental biotechnology.

Multimetal systems are often encountered in industrial operations. Three widely used metals which often appear in metal-bearing industrial effluents are copper, zinc, and cadmium. A recent study ${ }^{3}$ on the biosorption removal of these three metals using a new algal biosorbent material in two-metal systems shows that the equilibrium obeys the multicomponent Langmuir model. Three-dimensional sorption isotherm surfaces were used to evaluate the two-metal sorption system performance. Although this method can be extended to represent three-metal sorption equilibria (by a series of three-dimensional [3D] plots whereby the residual concentration of one of the metals is taken as a parameter), another graphical representation which could incorporate all the experimental data of the ternary system is desirable.

No biosorption equilibrium studies involving multiionic components have been reported so far. Apart from the difficulty of evaluating such systems, the experimental volume increases enormously with each additional ionic component present. Ion exchange has been proposed to be the most predominant mechanism of metal biosorption by algal materials. ${ }^{4}$ In the field of ion exchange, multicomponent equilibria have been extensively studied. ${ }^{1,15,17-19}$

The objectives of the present work were: (1) to present experimental equilibrium data for the ternary system containing $\mathrm{Cu}, \mathrm{Cd}$, and $\mathrm{Zn}$; (2) to examine if the multicomponent Langmuir sorption model could reasonably represent experimental data from biosorption equilibrium studies with the three-metal system; and (3) to verify the predictions of the three-metal system sorption behavior based on the information derived from the three two-metal subsystems. At the same time, another graphical representation of the ternary data was sought. While the experimental biosorption results for the respective component binary systems containing $\mathrm{Cu}+\mathrm{Cd}, \mathrm{Cu}+\mathrm{Zn}$, and $\mathrm{Cd}+\mathrm{Zn}$ have recently been published, ${ }^{3}$ this work represents an attempt in developing a framework from which the performance of a multicomponent (bio)sorption system may be estimated. 


\section{MATERIALS AND METHODS}

The biosorbent used was FCAN2, a sorbent material made from a brown alga Ascophyllum nodosum harvested from the Atlantic Ocean at Nova Scotia during the spring months. The raw dried seaweed was crushed and sized, and particles were crosslinked with formaldehyde ${ }^{10}$ and washed with distilled water $(3 \mathrm{~h}) .{ }^{5}$ Chemicals used were of analytical grade from Fisher Scientific. Aqueous solutions of the nitrates for the ions $\mathrm{Cu}(\mathrm{II})$, $\mathrm{Cd}$, and $\mathrm{Zn}$ were used.

The equilibrium distributions of ions in the solution and sorbent phases were determined by batch equilibrium techniques. Different equilibrium testing was also done by a "tea-bag" method in which the final residual equilibrium concentration of the metal in solution could be specified beforehand. The following is a brief description of both techniques.

\section{Batch Equilibrium Sorption Experiments}

Standard batch sorption equilibrium methodology applied has been described elsewhere. ${ }^{6,10,24}$ Weighed samples of FCAN2 $(100 \pm 2 \mathrm{mg})$ were added to $50 \pm 2 \mathrm{~mL}$ of solution with known initial metal concentration(s). Fifty-five samples, each containing different initial concentrations of the three metals were contacted until the sorption equilibrium was reached. The initial concentration of $\mathrm{Cu}$ ranged from 75 to $350 \mathrm{mg} / \mathrm{L}, \mathrm{Cd}$ from 100 to $700 \mathrm{mg} / \mathrm{L}$, and $\mathrm{Zn}$ from 125 to $400 \mathrm{mg} / \mathrm{L}$. Higher concentrations of $\mathrm{Cd}$ were chosen because it has a higher atomic weight than the other two metals. Molar concentration units were used in expressing the results of the present work because the weight-based metal uptakes are more practical only for engineering process calculations. The samples were shaken for $3 \mathrm{~h}$ at room temperature with hourly adjustment of $\mathrm{pH}$ to 4.5 by adding small amounts of diluted $\mathrm{HNO}_{3}$ or $\mathrm{NH}_{4} \mathrm{OH}$ as required. The $\mathrm{pH}$ remained relatively constant at $\mathrm{pH} 4.5( \pm 0.2)$ by the end of the third hour of contact. Buffering was not used due to unkown effects of buffer compounds on biosorption.

The final (residual) metal concentrations $C_{f}[\mathrm{M} 1]$, $C_{f}[\mathrm{M} 2]$, and $C_{f}[\mathrm{M} 3]$ in the solutions were determined by AAS (Thermo Jarrel Ash, Model Smith-Hieftje 11), leading to the respective calculated values for the biosorbent metal uptakes $q(\mathrm{M} 1), q(\mathrm{M} 2)$, and $q(\mathrm{M} 3)$ for the first, second, and third metal in each biosorption system, respectively, using the general definition ${ }^{24}$ :

$$
q(\mathrm{mmol} / \mathrm{g})=V\left(C_{i}-C_{f}\right) / m
$$

where $C_{i}$ is the initial metal concentration in solution of volume $V$, and $m$ is the mass of the biosorbent. Appropriate controls and blanks were examined throughout the sorption experiments to check the glassware sorption of metals and other potential side-effects.

\section{"Tea-Bag" Experiments}

Cellulose tissue was used to wrap $100 \pm 2 \mathrm{mg}$ of FCAN2 into a "tea-bag"-like configuration $(4 \times 4 \mathrm{~cm})$. For each batch of experiments, two "bags" were exposed for $24 \mathrm{~h}$ to approximately $6 \mathrm{~L}$ of known initial solution composition. The solution was mixed with a magnetic stirrer. Previous trial experiments indicated that an extended time period of 1 day was required for the biosorbent (inside the cellulose "bag") to reach equilibrium saturation due to diffusional sorption limitations.

At the end of the $24 \mathrm{~h}$, the final (residual) metal concentrations are approximately identical with the initial solution concentration (within the analytical accuracy of the AAS used). The metal-laden biosorbent in the "bag" was removed from the sorption system and was contacted with $100 \mathrm{~mL}$ of $1 M \mathrm{HNO}_{3}$ for another $24 \mathrm{~h}$ to desorb the sequestered metal. AAS was used to analyze the concentration of the metal fully eluted by $\mathrm{HNO}_{3}$ and thus, the amount of metal ions sorbed by the biosorbent could be determined. The empty bag control confirmed no metal uptake by the bag material.

\section{RESULTS AND DISCUSSION}

\section{Multicomponent Sorption Model Application}

Earlier work ${ }^{3}$ showed that the Langmuir and Freundlich equations best described the equilibria of the three twometal sorption systems of copper, cadmium, zinc, and biosorbent FCAN2. However, the extended binary Langmuir model not only represented the data in a very similar manner, but it also contained the least number of three parameters: the maximum uptake capacity $\left(q_{\max }\right)$ and two dissociation constants $(K)$ corresponding to each of the two metals. Because this simpler model was able to predict the binary sorption equilibria satisfactorily, it was further applied in describing the behavior of the three two-metal systems.

Correspondingly, the following extended multicomponent Langmuir model ${ }^{16}$ was examined as to whether it could represent the equilibrium data of the threemetal system studied in this work:

$$
q(\mathrm{M} i)=\frac{\left(q_{\max } / K_{i}\right) C_{f}[\mathrm{M} i]}{1+\left(1 / K_{1}\right) C_{f}[\mathrm{M} i]+\left(1 / \mathrm{K}_{2}\right) C_{f}[M 2]+\left(1 / K_{3}\right) C_{f}[\mathrm{M} 3]}
$$

where $i=(1$ to 3$)$ designates the metal in question.

Note that the model actually consists of three equations, one to compute the uptake of the first metal and other two for the uptakes of the second and the third metal, respectively. The denominators of the three equations are identical. The model contains four parameters: $q_{\max }, K_{1}, K_{2}$, and $K_{3}$. The computer program MATLAB (Version 4.0) was used to evaluate these parameters by minimizing the sum of squared residuals. 
Table I. Parameters of the multicomponent Langmuir model determined from binary and ternary experimental data.

\begin{tabular}{lccccc}
$\begin{array}{c}\text { Metal } \\
\text { system }\end{array}$ & $\begin{array}{c}K(\mathrm{Cu}) \\
(\mathrm{mmol} / \mathrm{L})\end{array}$ & $\begin{array}{c}K(\mathrm{Cd}) \\
(\mathrm{mmol} / \mathrm{L})\end{array}$ & $\begin{array}{c}K(\mathrm{Zn}) \\
(\mathrm{mmol} / \mathrm{L})\end{array}$ & $\begin{array}{c}q_{\mathrm{miax}} \\
(\mathrm{mmol} / \mathrm{g})\end{array}$ & $\begin{array}{c}\text { RMS, } \\
\text { error }\end{array}$ \\
\hline $\mathrm{Cd}+\mathrm{Zn}$ & - & 0.15 & 0.44 & 0.67 & \pm 5.4 \\
$\mathrm{Cu}+\mathrm{Cd}$ & 0.16 & 0.53 & - & 0.98 & \pm 8.2 \\
$\mathrm{Cu}+\mathrm{Zn}$ & 0.22 & - & 1.11 & 0.92 & \pm 3.4 \\
$\mathrm{Cu}+\mathrm{Cd}+\mathrm{Zn}$ & 0.88 & 3.16 & 6.34 & 1.14 & \pm 9.0 \\
\hline
\end{tabular}

$\mathrm{RMS}=$ root mean square.

The values of calculated parameters are shown in Table I together with those obtained from the binary systems.

The value of the apparent dissociation constant $K$ determined for a metal differed for each system. Likewise, $q_{\max }$ values for each respective system were not identical. For the $(\mathrm{Cu}+\mathrm{Cd}+\mathrm{Zn})$ system, a higher value of $K$ parameter for $\mathrm{Zn} \mathrm{(6.34)} \mathrm{than} \mathrm{for} \mathrm{Cd}$ (3.16) implies that FCAN2 has a higher affinity for Cd than for $\mathrm{Zn}$. While: a true quantiative judgment cannot be made, using a similar argument, it can also be concluded that there is stronger sorption by the biosorbent of $\mathrm{Cu}$ than of $\mathrm{Cd}$. Note that this could also be concluded from the $K$ values derived from the three binary systems as well as from one-metal sorption isotherms. ${ }^{3,6}$

The multicomponent Langmuir model has been used purely as a semiempirical method to correlate the sorption equilibria. In the ideal ion-exchange process, the values of equilibrium constants (selectivity constants) of both binary and "pseudo-binary" (ion exchange in the presence of the third ion) systems remain truly constant. ${ }^{20}$ Nonideality of ion-exchange systems has to be often considered to allow reasonable equilibrium predictions. The $K$ values have been known to vary, depending on the ions in question, with the ion-exchange resin loading and the solution concentration range. ${ }^{15}$ Most researchers have assigned single average values to these constants so that the experimental data could be represented. It is well known that the Langmuir model may sometimes not represent sorption behavior so well in lower concentration ranges. Moreover, experimental results from the ion-exchange study have also shown that $K$ in the ternary system does not always agree with the corresponding values from binary systems, ${ }^{11}$ similar to the case in the present work.

Similarly, the present biosorption system has to be defined as nonideal because the dissociation constants ( $K$ values) of the binary and ternary systems differ. This restricts the possibility of predicting ternary equilibria from the binary system data since there are no means of predicting the $K$ values for the ternary system from those of the three corresponding binary systems. However, some behavior of the ternary system, postulated from the information from the three binary subsystems, seems to be consistent with that predicted from the multicomponent Langmuir model as illustrated in this work.

To quantify the agreement between the model predictions and experimental observations for the behavior of the ternary system, an objective function relating the experimental and the predicted metal uptakes may be defined for each metal component ${ }^{18}$ :

$$
E_{i} \sum_{j=1}^{Q}\left(\frac{q_{i}^{\exp }-q_{i}^{\text {model }}}{q_{i}^{\exp }}\right)^{2}
$$

where $Q$ is the number of data points: $j=1 \ldots Q$.

Table II presents the values of the objective functions for each component. It indicates that of the three components, the predictions for the zinc uptake are the least accurate. The root-mean-square error (RMS) between experimental metal uptakes and those from model predictions is less than $\pm 10 \%$ for the ternary system considered, as reported in Table I.

Coventional sorption isotherms, plots of metal uptake by the biosorbent (in weight per weight or mole per weight units) as a function of the residual metal concentration in the solution (equilibrium concentration in weight or mole per volume units), are normally used to evaluate one-metal biosorption. A two-metal system can be graphically evaluated by using $3 \mathrm{D}$ plotting of the "sorption isotherm surface" instead. An example of 3D plots reflecting the equilibrium performance of twometal sorption by FCAN2 is presented in Figure 1 for the $(\mathrm{Cd}+\mathrm{Cu})$ system. Note that the system is characterized by at least two 3D diagrams. The sorption isotherm surfaces of the $(\mathrm{Cu}+\mathrm{Zn})$ and $(\mathrm{Cd}+\mathrm{Zn})$ systems have already been presented elsewhere ${ }^{3}$ and are not reproduced here. The limitation of this approach is obvious because the equilibrium data for three-metal system cannot be graphically depicted this way.

Table II. Comparison among component objective functions.

\begin{tabular}{cc}
\hline Component & $\begin{array}{c}E_{i} \\
\text { (dimensionless) }\end{array}$ \\
\hline $\mathrm{Cu}$ & 0.53 \\
$\mathrm{Cd}$ & 5.88 \\
$\mathrm{Zn}$ & 8.86 \\
Total metal & 0.78 \\
\hline
\end{tabular}



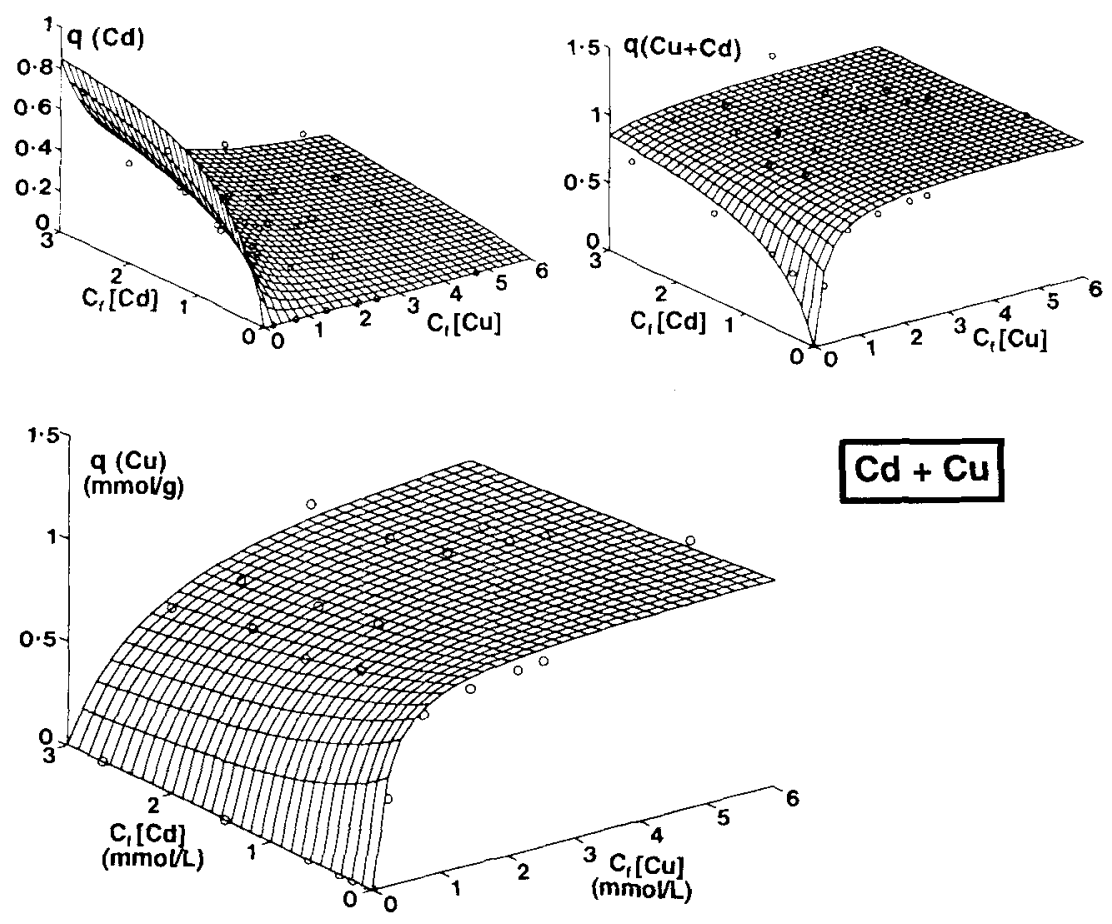

$\mathrm{Cd}+\mathrm{Cu}$

Figure 1. Sorption isotherm surfaces of the $(\mathrm{Cd}+\mathrm{Cu})$ system for FCAN2 biosorbent. The total and individual metal uptakes are plotted as a function of the final equilibrium concentrations of the two metals. All three possible plots for only one selected two-mctal system are presented as an example. Equilibrium contact at pH 4.5 and $22^{\circ}$ to $25^{\circ} \mathrm{C}$.

\section{Triangular Diagrams}

In the study of ion exchange equilibria, the third component is usually not included in graphical presentations. Brignal et al..$^{2}$ represented a ternary system in a triangular equilibrium diagram whereby the effect of the third ion is not ignored. Crist et al. ${ }^{4}$ showed that, for algae, biosorption of metal ions is accompanied by displacement of other cations, and thus an ion-exchange model is more consistent with the chemical system. Unfortunately, more experimental work needs to be performed to prove that the mechanism of biosorption by algal biosorbents is due predominantly to the ion exchange phenomenon. Nonetheless, the possibility of using a triangular diagram to graphically depict the equilibrium data of the $\mathrm{Cu}+\mathrm{Cd}+\mathrm{Zn}$ system examined here was tested. The results are shown as Figure $2 a-d$.

To use the triangular diagram, the equilibrium data were converted into their respective dimensionless forms by using mole fractions. The final residual concentrations and the metal uptakes were converted to metal fractions in solution and mole fractions in the sorbent, respectively. Experimental values used in Figure $2 \mathrm{a}-\mathrm{d}$ are summarized in Table III. The predicted and experimental metal uptakes are quite consistent over a large range of the total residual concentrations of the three metals. However, for total residual concentrations of $10 \mathrm{mmol} / \mathrm{L}$ and higher (about $40 \%$ of the data in Table III), the predicted and experimental metal uptakes of each metal deviate more than $10 \%$. Apart from this somewhat simplistic observation, further analysis would not yield any more insight.

There is no obvious trend in the present data which could be expressed. It is known that the Langmuir model gives an approximate representation of the system behavior at low concentrations, but it breaks down in the saturation region where the effects of molecular interactions become more pronounced. ${ }^{16} \mathrm{~A}$ much greater volume of experimental work would have to be completed to statistically treat the data set. As a random check, 10 experiments (Table III) were performed in duplicate, the results showing a reproducibility within $\pm 3 \%$. Only $60 \%$ of the data in Table III (whereby the multicomponent Langmuir model is able to predict the equilibrium data reasonably well) are depicted in the triangular diagrams illustrating the results of this work.

In the triangular diagram, the equidistant axes refer to the mole fractions of the respective metal species on the biosorbent. Superimposed on these axes are contour lines or parametric lines which, in Figures $2 a-c$, correspond to the mole fractions of copper, cadmium, and zinc in solution, respectively. There are obvious trends seen from these diagrams. It is possible to see the diagrams also as pseudo-4D plots (the result of projecting/ viewing a series of the surfaces over the Gibbs triangle $^{20.21}$ from above). For a complete description of the sorption system performance from the diagram, the value of the total concentration of the components in each phase is also required. 

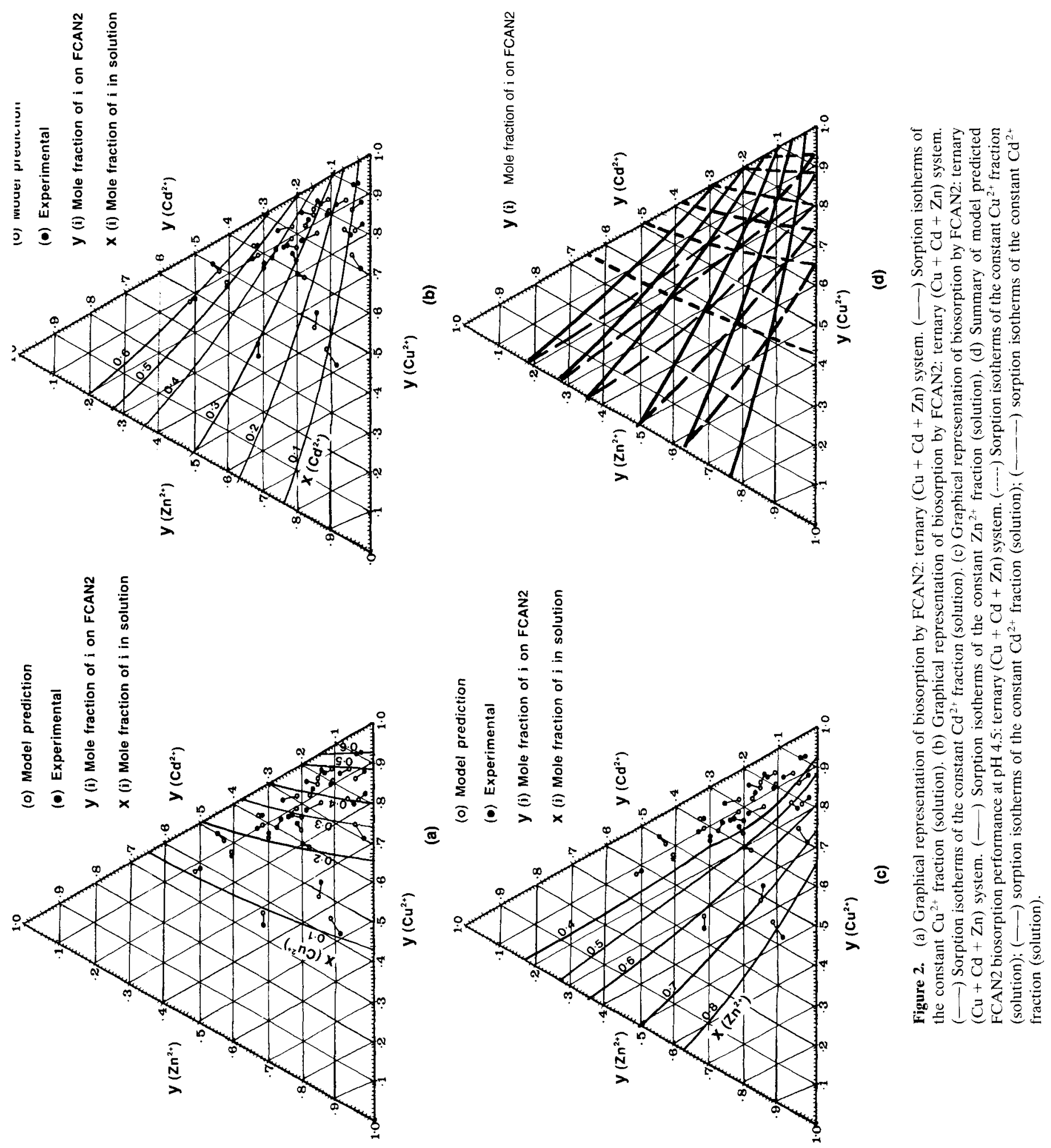
Table III. Comparison of experimental and calculated ternary equilibrium data for the $\left(\mathrm{Cu}^{2+}-\mathrm{Cd}^{2+}-\mathrm{Zn}^{2+}\right)$ system.

\begin{tabular}{|c|c|c|c|c|c|c|c|c|c|}
\hline \multirow{2}{*}{\multicolumn{3}{|c|}{$\begin{array}{l}\text { Solution-phase composition } \\
\text { (\% equiv.) }\end{array}$}} & \multicolumn{6}{|c|}{ Biosorbent-phase composition (\% equiv.) } & \multirow[b]{3}{*}{ Total $C_{f}(\mathrm{mmol} / \mathrm{L})$} \\
\hline & & & \multicolumn{3}{|c|}{ Experimental } & \multicolumn{3}{|c|}{ Calculated } & \\
\hline $\mathrm{Cu}^{2+}$ & $\mathrm{Cd}^{2+}$ & $\mathrm{Zn}^{2+}$ & $\mathrm{Cu}^{2+}$ & $\mathrm{Cd}^{2+}$ & $\mathrm{Zn}^{2+}$ & $\mathrm{Cu}^{2+}$ & $\mathrm{Cd}^{2+}$ & $\mathrm{Zn}^{2+}$ & \\
\hline 21.3 & 23.3 & 55.4 & 60.0 & 20.0 & 20.0 & 60.1 & 18.3 & 21.6 & 2.96 \\
\hline 13.5 & 14.9 & 71.6 & 53.3 & 14.23 & 2.5 & 49.1 & 15.0 & 35.9 & 4.97 \\
\hline 50.6 & 15.7 & 33.7 & 82.9 & 9.1 & 8.0 & 84.9 & 7.3 & 7.8 & 4.98 \\
\hline 15.3 & 52.8 & 31.9 & 47.8 & 33.3 & 18.9 & 44.6 & 42.6 & 12.8 & 5.42 \\
\hline 30.7 & 36.0 & 33.3 & 64.4 & 24.1 & 11.5 & 67.8 & 22.1 & 10.1 & 5.44 \\
\hline 61.7 & 12.7 & 25.6 & 90.7 & 4.1 & 5.2 & 89.7 & 5.1 & 5.1 & 6.63 \\
\hline 40.5 & 29.5 & 29.9 & 75.7 & 19.2 & 5.1 & 76.7 & 15.5 & 7.8 & 6.98 \\
\hline 11.4 & 10.9 & 77.7 & 42.2 & 9.6 & 48.2 & 45.2 & 12.1 & 42.7 & 7.13 \\
\hline 24.7 & 27.9 & 47.3 & 62.6 & 22.9 & 14.5 & 63.4 & 19.9 & 16.7 & 7.16 \\
\hline 12.1 & 60.8 & 27.1 & 39.0 & 50.6 & 10.4 & 37.1 & 51.5 & 11.4 & 7.17 \\
\hline 36.2 & 12.0 & 51.8 & 77.0 & $5.7=$ & 17.3 & 77.6 & 7.1 & 15.3 & 7.18 \\
\hline 35.6 & 39.9 & 24.5 & 68.4 & 25.5 & 6.1 & 71.2 & 22.1 & 6.7 & 7.30 \\
\hline 11.5 & 38.8 & 49.7 & 40.8 & 29.3 & 29.9 & 39.6 & 36.9 & 23.5 & 7.38 \\
\hline 24.5 & 48.7 & 26.8 & 56.8 & 34.1 & 9.1 & 58.7 & 32.4 & 8.8 & 7.39 \\
\hline 50.2 & 25.2 & 24.5 & 80.8 & 14.1 & 5.1 & 82.9 & 11.5 & 5.6 & 8.40 \\
\hline 33.5 & 24.7 & 41.8 & 69.0 & 19.3 & 11.7 & 72.6 & 14.9 & 12.5 & 8.45 \\
\hline 33.1 & 43.1 & 23.8 & 69.1 & 24.5 & 6.4 & 68.5 & 24.7 & 6.8 & 8.67 \\
\hline 46.6 & 9.7 & 43.7 & 87.6 & 3.1 & 9.3 & 84.3 & 4.8 & 10.9 & 8.71 \\
\hline 20.8 & 40.8 & 38.4 & 57.5 & 29.9 & 12.6 & 55.6 & 30.2 & 14.1 & 8.89 \\
\hline 45.4 & 33.7 & 20.9 & 81.7 & 15.4 & 2.9 & 78.8 & 16.2 & 5.0 & 8.95 \\
\hline 18.9 & 59.2 & 21.9 & 50.0 & 44.4 & 5.6 & 49.3 & 42.8 & 7.9 & 9.37 \\
\hline 28.1 & 31.2 & 40.7 & 65.2 & 23.5 & 11.3 & 66.3 & 20.4 & 13.3 & 9.40 \\
\hline 28.2 & 9.1 & 62.7 & 70.1 & 3.5 & 26.4 & 71.7 & 6.4 & 21.9 & 9.50 \\
\hline 28.5 & 50.2 & 21.3 & 73.4 & 22 & 83.8 & 62.9 & 30.7 & 6.5 & 9.54 \\
\hline 9.4 & 46.9 & 43.7 & 42.9 & 42.9 & 14.2 & 33.2 & 45.6 & 21.1 & 9.62 \\
\hline 9.5 & 29.9 & 60.6 & 34.4 & 31.8 & 33.8 & 36.4 & 31.7 & 31.9 & 9.77 \\
\hline 44.5 & 21.4 & 34.1 & 78.9 & 12.2 & 8.9 & 80.7 & 10.8 & 8.5 & 9.98 \\
\hline 29.3 & 37.5 & 33.2 & 63.9 & 23.7 & 12.4 & 66.2 & 23.4 & 10.3 & 10.06 \\
\hline 42.9 & 36.2 & 20.9 & 75.5 & 18.1 & 6.4 & 76.9 & 18.0 & 5.1 & 10.34 \\
\hline 26.7 & 53.5 & 19.8 & 61.2 & 32.7 & 6.1 & 60.3 & 33.5 & 6.2 & 10.61 \\
\hline 38.1 & 41.2 & 20.7 & 65.6 & 32.8 & 1.6 & 72.8 & 21.8 & 5.4 & 10.73 \\
\hline 16.6 & 51.8 & 31.6 & 46.1 & 40.7 & 13.2 & 47.0 & 40.6 & 12.3 & 10.89 \\
\hline 36.8 & 8.2 & 55.0 & 82.4 & 3.0 & 14.6 & 78.9 & 4.8 & 16.3 & 10.92 \\
\hline 36.5 & 27.4 & 36.1 & 82.8 & 12.1 & 5.1 & 74.4 & 15.5 & 10.1 & 11.20 \\
\hline 24.2 & 40.8 & 35.0 & 63.2 & 27.6 & 9.2 & 60.1 & 28.0 & 11.9 & 11.38 \\
\hline 36.1 & 32.5 & 31.4 & 74.8 & 16.8 & 8.4 & 73.0 & 18.2 & 8.8 & 11.69 \\
\hline 7.7 & 38.4 & 53.9 & 40.3 & 37.3 & 22.4 & 29.8 & 41.3 & 28.9 & 11.83 \\
\hline 23.9 & 25.0 & 51.1 & 52.7 & 25.3 & 22.0 & 63.1 & 18.3 & 18.6 & 11.85 \\
\hline 22.8 & 48.3 & 28.9 & 56.3 & 32.0 & 11.7 & 56.8 & 33.3 & 9.9 & 11.92 \\
\hline 25.8 & 29.9 & 44.3 & 64.9 & 21.7 & 13.4 & 64.2 & 20.6 & 15.2 & 12.09 \\
\hline 21.5 & 34.4 & 44.1 & 61.6 & 16.3 & 22.1 & 58.0 & 25.6 & 16.4 & 12.86 \\
\hline 20.7 & 34.0 & 45.3 & 43.6 & 40.0 & 16.4 & 56.9 & 25.8 & 17.2 & 12.93 \\
\hline 33.8 & 34.6 & 31.5 & 55.2 & 32.4 & 12.4 & 70.8 & 20.0 & 9.11 & 3.03 \\
\hline 31.9 & 22.7 & 45.4 & 79.5 & 9.6 & 10.9 & 71.8 & 14.2 & 14.0 & 13.82 \\
\hline 28.3 & 30.4 & 41.3 & 63.5 & 27.8 & 8.7 & 66.7 & 19.9 & 13.4 & 14.93 \\
\hline
\end{tabular}

In the study of ternary ion-exchange systems, it has been shown that deviations of the parametric lines from linearity are due to the nonideality of the system. ${ }^{20}$ Similarly, in this study of the ternary biosorption system, the nonlinearity of the contour lines in Figure $2 a-d$ confirms that the system is nonideal, as discussed earlier.

A comparison of the predicted ternary biosorption results with those actually obtained experimentally has been made in Figure 2a-c. For total residual concentrations of $10 \mathrm{mmol} / \mathrm{L}$ and lower in the $\mathrm{Cu}^{2+}-\mathrm{Cd}^{2+}-\mathrm{Zn}^{2+}$ system, deviations of the experimental points from those predicted by the Langmuir model are generally small. Large deviations, observed for a few data points, could be caused by some irregularity of sorption sites, affecting the distribution of the counterions. Due to the preference of FCAN2 for the metals examined which was $\mathrm{Cu}>\mathrm{Cd}>\mathrm{Zn}$, the experimental points tend to cluster toward the $\mathrm{Cu}$ corner with a conspicuous void in the $\mathrm{Zn}$ corner of the triangular diagram.

From the equations of the multicomponent model, 3D graphs can be simulated depicting the equilibrium behavior of the three-metal system. Because there is a 
preferential biosorbent selectivity for copper over zinc and cadmium, empirically selected "low" and "high" equilibrium concentrations of copper $(0.5$ and $5.0 \mathrm{~m} M$, respectively) were chosen as parameters to visualize a more pronounced difference between the two sorption isotherm surfaces of the $(\mathrm{Cd}+\mathrm{Zn})$ systems as depicted in Figures 3 to 5. Figures $3 \mathrm{a}, 4 \mathrm{a}$, and 5a show the 3D sorption isotherm plots of different possible metal uptakes on the vertical axes while Figures $3 b, 4 b$, and $5 b$ represent the same data but the plots are shown viewed from a different angle to better reveal their shapes. There is a marked difference between the shape of the two isotherm surfaces for the $\mathrm{Cd}+\mathrm{Zn}$ system as illustrated in Figure "b": at $C_{f}(\mathrm{Cu})=5 \mathrm{~m} M$, the isotherm surfaces seem to approximate flat planes, but at $C_{f}(\mathrm{Cu})$ $=0.5 \mathrm{~m} M$, the isotherm surfaces resemble more the curved conventional shape of the Langmuir plot. From Figures 3 and 4 , one could estimate that for $C_{f}(\mathrm{Cu})=$ $0.5 \mathrm{~m} M$, the maximum zinc uptake is approximately $0.4 \mathrm{mmol} / \mathrm{g}$, while that for cadmium is considerably higher. This again implies a substantial sorption preference of FCAN2 for cadmium over zinc. Figure 4 shows that the isotherm surface at $C_{f}(\mathrm{Cu})=0.5 \mathrm{~m} M$ displays much more pronounced curvature and twist while that at $C_{f}(\mathrm{Cu})=5 \mathrm{~m} M$ is closer to a flat surface. All these


Figure 3. Simulation of the sorption isotherm surfaces of the $\mathrm{Cu}+$ $\mathrm{Cd}+\mathrm{Zn}$ systems with $C_{f}(\mathrm{Cu})$ as a parameter: $q(\mathrm{Cd})$ as a function of $C_{f}(\mathrm{Zn})$ and $C_{f}(\mathrm{Cd})$. Note: (a) and (b) are the same plots shown from different viewing angles to better reveal their respective shapes.
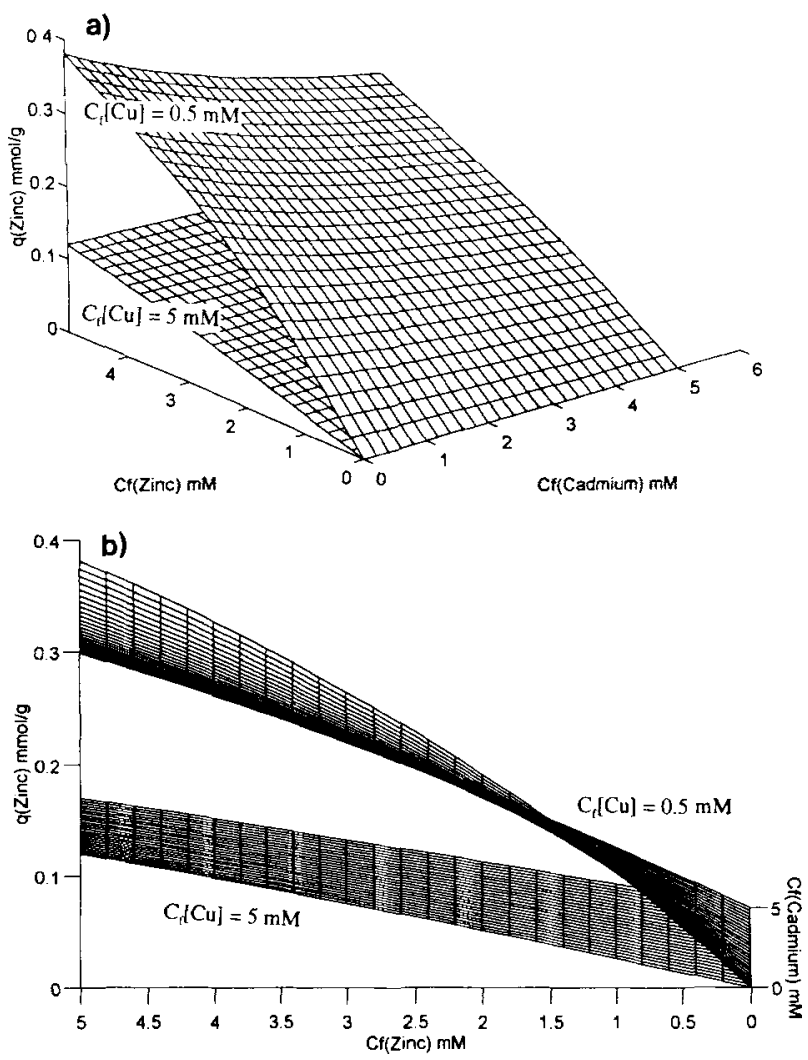

Figure 4. Simulation of the sorption isotherm surfaces of the $\mathrm{Cu}+$ $\mathrm{Cd}+\mathrm{Zn}$ systems with $C_{f}(\mathrm{Cu})$ as a parameter: $q(\mathrm{Zn})$ as a function of $C_{f}(\mathrm{Zn})$ and $C_{f}(\mathrm{Cd})$. Note: (a) and (b) are the same plots shown from different viewing angles to better reveal their respective shapes.

phenomena could also be seen from Figure 5 which is actually the outcome of the addition of the two previous figures (Figs. 3 and 4).

\section{Predictions Based on Two-Metal Data}

From the information on the three two-metal systems, some predictions can be made as to the possible behavior of the ternary $\mathrm{Cu}+\mathrm{Cd}+\mathrm{Zn}$ systems. Two cases can be considered:

1. Equal equilibrium metal concentrations (in solution). The amount of metal deposited on the sorbent material (percent metal uptake by FCAN2 biosorbent) in a three-metal system (regardless of "low" or "high" residual concentrations) will then be: copper, $55 \%$ to $71 \%$; cadmium, $20 \%$ to $34 \%$; and zinc, $8 \%$ to $14 \%$.

2. Equal uptakes for all three metals will result when: the equilibrium (residual) molar concentration of cadmium in solution would be 1.7 to 3.5 times higher than that of copper; the equilibrium molar concentration of zinc would be 5 to 10.5 times higher (in solution) than that of copper; and the equilibrium molar concentration of zinc would be 1.4 to 3 times higher than that of cadmium.

The predicted "ranges" arise from the fact that the values of apparent dissociation constants $(K)$ for a metal 

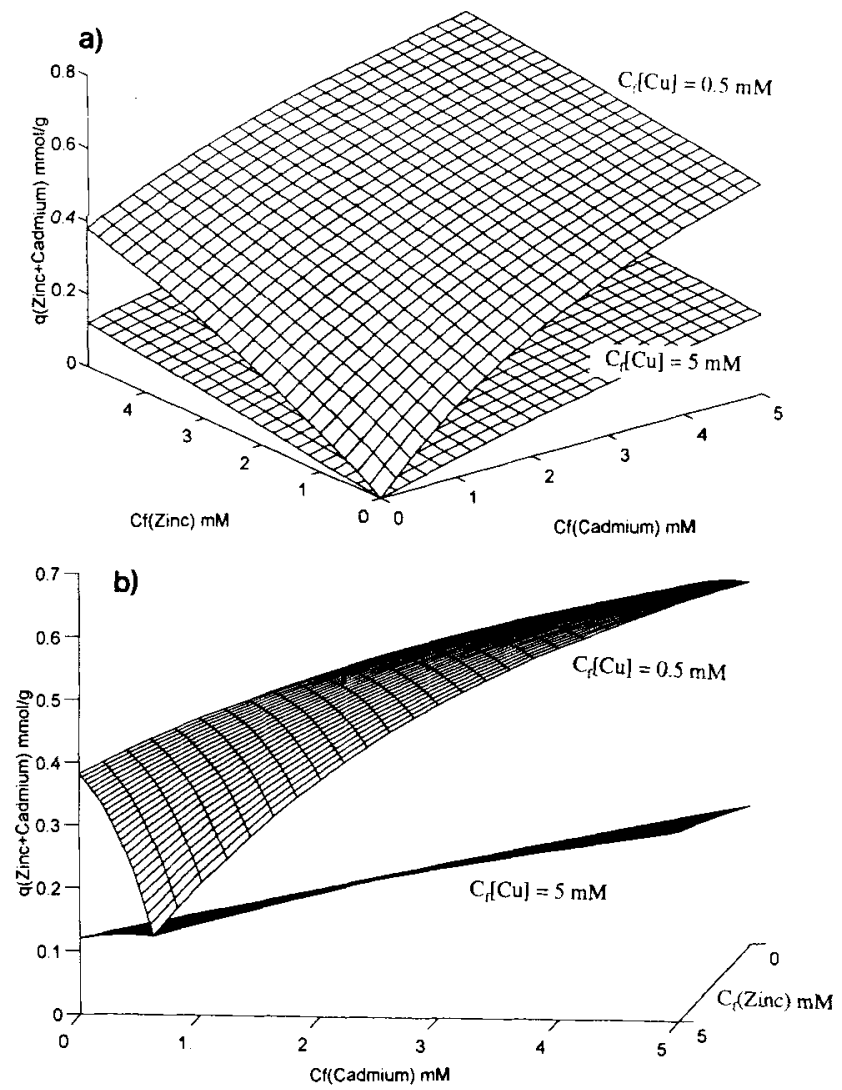

Figure 5. Simulation of the sorption isotherm surfaces of the $\mathrm{Cu}+$ $\mathrm{Cd}+\mathrm{Zn}$ systems with $C_{f}(\mathrm{Cu})$ as a parameter: $q(\mathrm{Cd}+\mathrm{Zn})$ as a function of $C_{f}(\mathrm{Zn})$ and $C_{f}(\mathrm{Cd})$. Note: (a) and (b) are the same plots shown from different viewing angles to better reveal their respective shapes.

in one two-metal system are different from those for another two-metal system.

\section{Predictions Based on Three-Metal Data}

Similar types of predictions can be obtained from the multicomponent Langmuir model whereby its parameters had been evaluated from the experimental data of the sorption system containing all the three metals together. The same two cases as above could be examined.

1. For the same residual concentration of each metal (regardless of "low" or "high" equilibrium concentrations), the predicted percent metal uptakes by FCAN2 are: copper, $70.6 \%$; cadmium, $19.6 \%$; and zinc, $9.7 \%$.

2. For the same amount of each metal to be sequestered by the biosorbent, the ratio of residual equilibrium concentrations $C_{f}[\mathrm{Zn}]: C_{f}[\mathrm{Cd}]: C_{f}[\mathrm{Cu}]$ : would have to be $7.25: 3.61: 1$.

Note that all these results, obtained from the multicomponent Langmuir model through experimental results, fall within the predicted "ranges" postulated from the results of the three binary subsystems.
In the study of ion exchange, when two binary systems are chosen which contain the most preferred ion in each of them, the computed ternary data will agree very well with the experimental data. ${ }^{1,17}$ In the present work, from the data on the binary sorption system including the most preferred ion, $\mathrm{Cu}$, the following is the prediction of mole fractions of ions (in the sorbent) at the same residual concentration of each metal (in solution): $\mathrm{Cu}$ 66.5\%; $\mathrm{Cd} 19.8 \%$; and $\mathrm{Zn} 13.6 \%$. The molar ratio of a component in solution, when the percent metal uptake for each component is equal, was computed to be $5: 3.5: 1$. These predictions are very consistent with those obtained from the model except for those involving zinc. As stated earlier, the component objective function showed that the prediction of zinc uptake is the least accurate.

\section{"Tea-bag" Experimental Confirmation}

The "tea-bag" experiment (more appropriately used for biosorbent screening purposes), as described earlier, was used to verify if the multicomponent Langmuir model could predict the equilibrium data of the threemetal system reasonably well. The advantage of the "tea-bag" experiment is that one could control the desired equilibrium concentrations of the three metals. As such, it would be of interest in verifying the predictions obtained from the multicomponent Langmuir model. Table IV shows that the computed metal uptakes are quite consistent with the experimental uptakes. This, in turn, means that a comparison of the ternary data postulated from the model, and of those obtained experimentally, exhibits a good agreement. Hence, the somewhat unconventional "tea-bag" technique is further confirmed as a verification tool when there is a necessity to predict the sorption performance at a specified final (residual) equilibrium concentration.

\section{Metal Sorption Selectivity}

Results from the ternary data also imply that the metal selectivity of FCAN2 is of the order $\mathrm{Cu}>\mathrm{Cd}>\mathrm{Zn}$. This is in full accord with results obtained earlier. ${ }^{3.6}$ Table $\mathrm{V}$ shows some properties of the three divalent ions. An earlier work ${ }^{22}$ using $R$. arrhizus showed that there was a linear correlation between the maximum biosorption metal uptake and ionic radius. The fact that $\mathrm{Cu}^{2+}$ has the smallest ionic radius, and it is the most sorbed ion among the three ions examined, indicates that the conclusion by Tobin et al. ${ }^{22}$ may not apply to algal biosorbent. $\mathrm{Zn}^{2+}$ has a smaller ionic radius than $\mathrm{Cd}^{2+}$ but it is sorbed the least. It is possible that because $\mathrm{Cd}^{2+}$ has a lower charge density, its hydration energy is lower. With less interaction between water molecules and $\mathrm{Cd}^{2+}$ ions, interaction between FCAN2 and $\mathrm{Cd}^{2+}$ ions increases. $\mathrm{Cu}^{2+}$ ions have one unpaired electron and should be paramagnetic. ${ }^{12}$ They are thus capable 
Table IV. Comparison between "lea-bag" experimental metal uptakes" and multicomponent Langmuir model predictions.

\begin{tabular}{|c|c|c|c|c|c|c|c|}
\hline & & Copper & $\begin{array}{c}\text { Deviation } \\
(\%)\end{array}$ & Cadmium & $\begin{array}{c}\text { Deviation }^{\mathrm{b}} \\
(\%)\end{array}$ & Zinc & $\begin{array}{c}\text { Deviation }^{\mathrm{b}} \\
(\%)\end{array}$ \\
\hline$C_{f}$ & $(\mathrm{mmol} / \mathrm{L})$ & 3.0 & & 2.9 & & 3.3 & \\
\hline$q(\exp ) 1$ & $(\mathrm{mmol} / \mathrm{g})$ & 0.61 & -6.0 & 0.21 & +16.6 & 0.11 & +10.0 \\
\hline$q(\exp ) 2$ & $(\mathrm{mmol} / \mathrm{g})$ & 0.61 & -6.0 & 0.19 & +5.5 & 0.10 & 0.0 \\
\hline$q($ model $)$ & $(\mathrm{mmol} / \mathrm{g})$ & 0.66 & & 0.18 & & 0.10 & \\
\hline$C_{f}(\mathrm{mmol} / \mathrm{L})$ & & 5.0 & & 4.8 & & 5.1 & \\
\hline$q(\exp ) 1$ & $(\mathrm{mmol} / \mathrm{g})$ & 0.78 & +8.3 & 0.21 & +10.5 & 0.11 & +10.0 \\
\hline$q(\exp )^{2}$ & $(\mathrm{mmol} / \mathrm{g})$ & 0.76 & +5.5 & 0.23 & +21.0 & 0.12 & +20.0 \\
\hline$q($ model $)$ & $(\mathrm{mmol} / \mathrm{g})$ & 0.72 & & 0.19 & & 0.10 & \\
\hline$C_{f}$ & $(\mathrm{mmol} / \mathrm{L})$ & 4.72 & & 2.73 & & 4.77 & \\
\hline$q(\exp ) 1$ & $(\mathrm{mmol} / \mathrm{g})$ & 0.78 & +1.3 & 0.12 & 0.0 & 0.13 & +18.0 \\
\hline$q(\exp )^{2}$ & $(\mathrm{mmol} / \mathrm{g})$ & 0.81 & +5.2 & 0.14 & +16.6 & 0.15 & +36.0 \\
\hline$q($ model $)$ & $(\mathrm{mmol} / \mathrm{g})$ & 0.77 & & 0.12 & & 0.11 & \\
\hline$C_{f}$ & $(\mathrm{mmol} / \mathrm{L})$ & 1.0 & & 3.6 & & 7.2 & \\
\hline$q(\exp ) 1$ & (mmol/g) & 0.42 & +5.0 & 0.40 & +2.5 & 0.37 & -5.0 \\
\hline$q(\exp ) 2$ & $(\mathrm{mmol} / \mathrm{g})$ & 0.38 & -5.0 & 0.39 & 0.0 & 0.36 & -7.7 \\
\hline$q($ model $)$ & $(\mathrm{mmol} / \mathrm{g})$ & 0.40 & & 0.39 & & 0.39 & \\
\hline
\end{tabular}

${ }^{a}$ Designated as $q(\exp ) 1$ and $q(\exp ) 2$.

${ }^{\mathrm{b}} \%$ Deviation $\left.=100[q(\exp )-q(\bmod )] / q(\bmod )\right]$.

of being attracted to a magnetic field possibly originating from the sorbent. $\mathrm{Zn}$ and $\mathrm{Cd}$ ions are very stable (no unpaired electron) and they are slightly repelled by a magnetic field. Moreover, there are two possible coordination numbers $(2,4)$ associated with $\mathrm{Cu}^{2+}$ as compared to only one for $\mathrm{Cd}^{2+}(4)$ and $\mathrm{Zn}^{2+}$ (4). If the systems form complexes in the sorbent phase, then $\mathrm{Cu}^{2+}$ (the least stable among the three investigated) only required two more electrons to do so as compared with $\mathrm{Cd}^{2+}$ and $\mathrm{Zn}^{2+}$ which both require four electrons. As the electronegativity of the atom increases, its ionic forms seems to be more easily sorbed by the biosorbent.

While these are just hypotheses pertaining to the preferential uptake of $\mathrm{Cu}$ over $\mathrm{Cd}$ and $\mathrm{Zn}$ by FCAN2, more in-depth study is required to elucidate the basis for metal biosorption preferences. Metal sorption selectivity provides the key to metal purification/enrichment performance essential for metal recovery processes.

Although the procedure of fitting the multicomponent Langmuir model to the ternary data is semiempiri-

Table V. Some physical and chemical properties of the three ions.

\begin{tabular}{|c|c|c|c|}
\hline & $\mathrm{Cu}^{2+}$ & $\mathrm{Cd}^{2+}$ & $\mathrm{Zn}^{2+}$ \\
\hline Ionic radius $(\AA)$ & 0.72 & 0.97 & 0.74 \\
\hline Charge & 2 & 2 & \\
\hline Charge density & 2.8 & 2.1 & 2.7 \\
\hline $\begin{array}{l}\text { Coordination } \\
\text { number }\end{array}$ & 2,4 & 4 & 4 \\
\hline $\begin{array}{l}\text { Electron } \\
\text { configuration }\end{array}$ & {$[\mathrm{Ar}] 3 \mathrm{~d}^{9}$} & {$[\mathrm{Kr}] 4 \mathrm{~d}^{10}$} & {$[\mathrm{Ar}] 3 \mathrm{~d}^{16}$} \\
\hline $\begin{array}{c}\text { Electronegativity } \\
\text { of the atom }\end{array}$ & 1.9 & 1.7 & 1.6 \\
\hline
\end{tabular}

cal, some predictions of the behavior of a ternary metal system are in a reasonably good agreement with experimental results and those derived from the three binary systems. A triangular diagram technique has been successfully implemented here for the graphic representation of the ternary biosorption data. It can be anticipated that the dimensionless equilibrium concentration distribution of metal compositions in a four-component sorption system may be conveniently represented in a 3D form as points within a regular tetrahedron. ${ }^{16}$ In this work, a framework has been outlined for evaluation of metal biosorption performance in a ternary system using original data with a new biosorbent.

The contribution of the FCAR Quebec Scholarship to K. H. Chong is gratefully acknowledged.

\section{References}

1. Bajpai, R. K., Gupta, A. K., Gopala Rao, M. 1973. Binary and ternary ion-exchange equilibria. Sodium-cesium-manganesedowex 50W-X8 and cesium-manganese-strontium-dowex 50WX8 systems. J. Phys. Chem. 77: 1288-1294.

2. Brignal, W. J., Gupta, A. K., Streat, M. 1976. Representation and interpretation of multicomponent ion exchange equilibria. In: Theory and Practice of Ion Exchange, an International Conference. Cambridge University Press. Cambridge, UK.

3. Chong, K. H., Volesky, B. 1995. Description of 2-metal biosorption equilibria by Langmuir-type models. Biotechnol. Bioeng. 47: $451-460$.

4. Crist, R. H., Martin, J. R., Carr, D., Watson, J. R., Clarke, H. J., Crist, D. R. 1994. Interaction of metals and protons with algae. 4. Ion exchange vs adsorption models and reassessment of Scatchard plots; ion-exchange rates and equilibria compared with calcium alginate. Environ. Sci. Technol. 28: 1859-1866. 
5. de Carvalho, R. P., Chong, K. -H., Volesky, B. 1994. Effects of leached alginate on metal biosorption. Biotechnol. Lett. 46: 875-880.

6. de Carvalho, R. P., Chong, K. -H., Volesky, B. 1995. Evaluation of the $\mathrm{Cd}, \mathrm{Cu}$ and $\mathrm{Zn}$ biosorption in two-metal systems using algal biosorbent. Biotechnol. Prog. 11: 39-44.

7. Fourest, E., Roux, J. C. 1994. Improvement of heavy metal biosorption by mycelial dead biomass (Rhizopus arrhizus, Mucor miehei and Penicillium chrysogenum): $\mathrm{pH}$ control and cationic activation. FEMS Microbiol. Rev. 14: 325-332.

8. Greene, B., McPherson, R. A., Darnall, D. W. 1987. Algal sorbents for selective metal ion recovery, p. 315. In: J. Patterson and R. Pasino (eds.), Metals speciation, separation and recovery. Lewis, Chelsea, MI.

9. Holan, Z. R., Volesky, B. 1994. Biosorption of lead and nickel by seaweed materials. Biotechnol. Bioeng. 43: 1001-1009.

10. Holan, Z. R., Volesky, B., Prasetyo, I. 1993. Biosorption of cadmium by biomass of marine algae. Biotechnol. Bioeng. 41: $819-825$.

11. Kataoka, T., Yoshida, H. 1980. Ion exchange equilibria in ternary systems. J. Chem. Eng. Jpn. 13: 328-330.

12. Kotz, J. C., Purcell, K. F. 1991. In: pp. 318-321, 332-338. Chemistry and reactivity, 2nd edition. Saunders, Philadelphia.

13. Kuyucak, N., Volesky, B. 1989. Accumulation of gold by algal biosorbent. Biorecovery 1: 189-204.

14. Niu, H., Xu, X. S., Wang, J. H., Volesky, B. 1993. Removal of lead from aqueous solutions by Penicillium biomass. Biotechnol. Bioeng. 42: 785-787.
15. Pieroni, L. J., Dranoff, J. S. 1963. Ion exchange equilibria in a ternary system. AIChE J. 9: 42-45.

16. Ruthven, D. M. 1984. p. 124-272. Principles of adsorption and adsorption processes. Wiley, New York.

17. Sengupta, M., Paul, T. B. 1985. Multicomponent ion exchange equilibria: I. $\mathrm{Zn}^{2+}-\mathrm{Cd}^{2+}-\mathrm{H}^{+}$and $\mathrm{Cu}^{2+}-\mathrm{Ag}^{2+}-\mathrm{H}^{+}$on Amberlite IR120. React. Polym. 3: 217-229.

18. Shallcross, M., Herrmann, C. C., McCoy, B. J. 1988. An improved model for the predictin of multicomponent ion exchange equilibria. Chem. Eng. Sci. 43: 279-288.

19. Smith, R. P., Woodburn, E. T. 1978. Prediction of system $\mathrm{So}_{4}^{2-}-$ $\mathrm{NO}_{3}^{-}-\mathrm{Cl}^{-}$from data of binary systems. AIChE J. 24: 577-587.

20. Soldatov, V. S., Bichkova, V. A. 1980. Ternary ion-exchange equilibria. Sep. Sci. Technol. 15: 89-110.

21. Soldatov, V. S., Bichkova, V. A. 1985. Binary ion exchange selectivity coefficients in multiionic systems. React. Polym. 3: 199-206.

22. Tobin, J. M., Cooper, D. G., Neufeld, R. J. 1984. Uptake of metal ions by Rhizopus arrhizus biomass. Appl. Microbiol. 47: 821-824.

23. Tsezos, M. 1986. Adsorption by microbial biomass as a process for removal of ions from process or waste solutions, pp. 201-226. In: H. H. Eccles and S. Hunt (eds.), Immobilisation of ions by biosorption. Ellis Horwood, Chichester, West Sussex, UK.

24. Volesky, B. 1990. Removal and recovery of heavy metals by biosorption, pp. 7-44. In: B. Volesky (ed.), Biosorption of heavy metals. CRC Press, Boca Raton, FL.

25. Volesky, B., Holan, Z. R. 1995. Biosorption of heavy metals. Biotechnol. Prog. 11: 235-250. 